\title{
O uso de estratégias diversificadas e dialógicas no ensino sobre o filo Arthropoda: relato de experiência das contribuições do estágio supervisionado
}

\author{
The use of diversified and dialogic strategies in teaching about the Arthropoda phylum: experience \\ report of the contributions of supervised internship \\ El uso de estrategias diversificadas y dialógicas en la enseñanza sobre el filo Arthropoda: relato de \\ experiencia de los aportes de la pasantía supervisada
}

Recebido: 28/09/2021 | Revisado: 06/10/2021 | Aceito: 20/10/2021 | Publicado: 22/10/2021
Kévila Kelma Nascimento Silva dos Passos ORCID: https://orcid.org/0000-0001-9265-0622 Universidade Federal de Itajubá, Brasil E-mail: kevilakelma@gmail.com

\begin{abstract}
Resumo
Este trabalho consiste em um relato de experiência desenvolvida durante a disciplina Estágio Supervisionado de um curso de Licenciatura em Ciências Biológicas. Descreve e reflete sobre a experiência de regência, desenvolvimento e aplicação de estratégias e instrumentos didáticos diversificados e dialógicos no ensino sobre anatomia, morfologia e importância ecológica do filo Arthropoda. A metodologia didática se desenvolveu em quatro fases: Problematização inicial; Desenvolvimento da narrativa do ensino; Aplicando os conhecimentos; e por fim, Refletindo sobre o que foi aprendido. Com o uso de estratégias diversificadas e dialógicas, observou-se resultados positivos na aprendizagem dos alunos, não somente de conteúdos conceituais mas, também procedimentais e atitudinais importantes para a formação crítica e conscientização sobre preservação ambiental. Além de auxiliar na motivação e participação ativa dos alunos. Conclui-se que a práxis promovida pelas atividades desenvolvidas durante o Estágio Supervisionado foi fundamental para a consolidação dos conhecimentos construídos durante a graduação, sendo uma etapa fundamental para a formação e futura atuação docente.
\end{abstract}

Palavras-chave: Estágio Supervisionado; Formação docente; Artrópodes; Instrumentos didáticos; Estratégias didáticas.

\begin{abstract}
This work consists of an experience report developed during the Supervised Internship discipline of a Licentiate Degree in Biological Sciences. Describes and reflects on the experience of conducting, developing and applying diversified and dialogical strategies and didactic instruments in teaching about anatomy, morphology and ecological importance of the Arthropoda phylum. The didactic methodology was developed in four phases: Initial problematization; Development of the teaching narrative; Applying knowledge; and finally, Reflecting on what was learned. With the use of diversified and dialogic strategies, positive results were observed in the students' learning, not only regarding conceptual content, but also procedural and attitudinal important for critical training and awareness of environmental preservation. In addition to assisting in the motivation and active participation of students. It is concluded that the praxis promoted by the activities developed during the Supervised Internship was fundamental for the consolidation of the knowledge built during graduation, being a fundamental step for the formation and future teaching performance.
\end{abstract}

Keywords: Supervised internship; Teacher training; Arthropods; Didactic instruments; Didactic strategies.

\footnotetext{
Resumen

Este trabajo consiste en un informe de experiencia desarrollado durante la disciplina de Pasantía Supervisada de la Licenciatura en Ciencias Biológicas. Describe y reflexiona sobre la experiencia de conducir, desarrollar y aplicar estrategias e instrumentos didácticos diversificados y dialógicos en la enseñanza de la anatomía, morfología e importancia ecológica del filo Arthropoda. La metodología didáctica se desarrolló en cuatro fases: Problematización inicial; Desarrollo de la narrativa didáctica; Aplicar conocimientos; y finalmente, Reflexionando sobre lo aprendido. Con el uso de estrategias diversificadas y dialógicas, se observaron resultados positivos en el aprendizaje de los estudiantes, no solo en cuanto a contenidos conceptuales, sino también procedimentales y actitudinales importantes para la formación crítica y conciencia de la preservación ambiental. Además de ayudar en la motivación y participación activa de los estudiantes. Se concluye que la praxis promovida por las actividades desarrolladas durante
} 
la Pasantía Supervisada fue fundamental para la consolidación de los conocimientos construidos durante la graduación, siendo un paso fundamental para la formación y el desempeño docente futuro.

Palabras clave: Pasantía supervisada; Formación de profesores; Artrópodos; Instrumentos didácticos; Estrategias didácticas.

\section{Introdução}

Práticas pedagógicas com viés filosófico positivista são uma realidade em grande parte das salas de aula brasileiras, onde os conteúdos conceituais são apresentados como um conjunto de conceitos e teorias científicas de maneira organizada, contínua e muitas vezes fragmentada e descontextualizada. Essas práticas geram uma falsa imagem de sucesso escolar uma vez que não contribuem para os processos de pensar e agir dos alunos, sendo insuficientes ao seu processo formativo (Lima, Aguiar \& Braga, 2000). Correia et al. (2021) argumentam que diante da necessidade de se oferecer uma educação integral aos jovens tais práticas se mostram como filosoficamente equivocadas e pedagogicamente ineficientes. Além de serem práticas ultrapassadas, já que não despertam o interesse e engajamento dos alunos (Araújo \& Lopes Neta, 2017).

O Ensino de Biologia comumente é estruturado pela sistemática onde predomina o nível descritivo dos conteúdos, condizente com a filosofia positivista. Essa postura, muitas vezes, reproduz técnicas de memorização dos conteúdos, e não uma verdadeira aprendizagem, tornando os alunos simples ouvintes (Rossasi \& Polinarski, 2007; Achterberg, Centa, \& Terrazzan, 2021). Com certa frequência, esses conteúdos são distantes da realidade, dos aspectos culturais, históricos e sociais dos alunos. Sendo essa falta de aproximação com a realidade um dos fatores responsáveis pelo insucesso escolar (Lima et Al, 2000; Marques Filho et al., 2021). Diante desse cenário, destaca-se a importância em se perscrutar a gama de informações às quais os alunos têm acesso diante do desenvolvimento tecnológico, no qual eles são imersos de maneira acelerada e recorrente. Urge então, a necessidade da busca docente por instrumentos e estratégias diversificadas “... que vão além do uso do computador e smartphone em sala de aula. O ambiente da instituição precisa ser inovador e deve estar aberto a novas possibilidades de ações e recursos capazes de transformar o ambiente e o ser humano" (Cabral \& Stahl, 2021, p. 52790).

Mediante a isso, há de se questionar as práticas docentes, no que se refere ao uso, quase exclusivo, do quadro-negro e do livro didático de forma sistemática. Nessa dinâmica o professor se torna apenas mais uma fonte de informação, por vezes menos interessante e atraente, ante a tantas outras (Alarcão, 2007; Camargo \& Daros, 2018). O grande acesso às tecnologias da informação e comunicação torna mais amplas as possibilidades da interação do professor com seus alunos e deles com o conhecimento científico. A utilização adequada e dialógica de diferentes tecnologias, torna-se um auxiliar nos processos educacionais ao ser utilizada de modo consciente e planejado (Pereira \& Freitas, 2021; Vieira Júnior \& Melo, 2021).

De acordo com a autora Oliveira (2015) e os autores Barbosa, Mariano \& Sousa (2021), o público escolar possui acesso a informações mais atraentes que aquelas oferecidas pela escola. Com todo o avanço tecnológico disponível e os diversificados perfis de alunos, há a necessidade de que o docente se adeque a esse novo público, despertando o interesse pelo conhecimento e o trabalho científico e ainda, favorecer o desenvolvimento da inovação e das noções sobre o "ensinar" e o “aprender” na Educação Básica. Perfis diversos demandam estratégias e instrumentos diversos e dialógicos umas vez que esses serão úteis na reconstrução da memória e na consolidação do conhecimento ao cotidiano do aluno (Terçariol et al., 2021).

Araújo et al. (2017) e Bastos (2008) recomendam a introdução de novas e diversificadas estratégias e instrumentos que podem inclusive ser trabalhados em sintonia para a melhoria da prática educativa. Em conformidade, Castilho, Araújo \& Parreira Jr. (2020) e Gadotti (2003) destacam que ministrar o conteúdo com estratégias apropriadas, além de respeitar o aluno resgata sua identidade. O uso de estratégias inadequadas pode negar ao aluno o direito de afirmação de sua identidade, de seu saber e até mesmo de sua cultura.

Diante desse cenário, surge a demanda por aulas mais dinâmicas, atrativas, dialógicas com uma diversidade de 
estratégias de ensino a fim de alcançar o diverso público escolar. Para isso, é necessária uma observação atenta do ambiente escolar, das necessidades e exigências da prática docente, das condições da escola e do interesse de seus alunos. Desde modo, o professor pode selecionar as estratégias e instrumentos que melhor se adequem para aquela situação, público e conteúdo com material potencialmente significativo, resultando em contribuição para a aprendizagem dos conceitos científicos (Rossasi \& Polinarski, 2007; Lozada et al., 2021).

Contudo, essa necessária alteração nos modos de ensinar e aprender exigem uma troca de conhecimentos entre docentes e discentes em uma relação de confiança em que o diálogo é uma ferramenta educacional. Freire (2005, p.79) argumenta que: "O educador já não é mais o que educa, mas o que, enquanto educa, é educado, em diálogo com o educando que, ao ser educado, também educa. Ambos, assim, se tornam sujeitos do processo em que crescem juntos."

Para tal, as disciplinas de Estágio Supervisionado durante os cursos de Licenciatura se mostram como um campo fértil para a promoção desse primeiro contato dialógico entre educandos e educadores, sendo fundamental para o processo formativo do futuro docente. De acordo com art. $1^{\circ}$ da Lei Federal 11.788 (2008):

Art. 1ํㅡㄹ Estágio é ato educativo escolar supervisionado, desenvolvido no ambiente de trabalho, que visa à preparação para o trabalho produtivo de educandos que estejam frequentando o ensino regular em instituições de educação superior, de educação profissional, de ensino médio, da educação especial e dos anos finais do ensino fundamental, na modalidade profissional da educação de jovens e adultos.

$\S 1$ o $\mathrm{O}$ estágio faz parte do projeto pedagógico do curso, além de integrar o itinerário formativo do educando.

$\S 2$ O $\mathrm{O}$ estágio visa ao aprendizado de competências próprias da atividade profissional e à contextualização curricular, objetivando o desenvolvimento do educando para a vida cidadã e para o trabalho. (Lei Federal 11.788, 2008).

O Estágio Supervisionado é imprescindível para a formação de professores, pois ele é o primeiro espaço onde o professor em formação tem a oportunidade de conhecer e refletir sobre as dinâmicas da sala de aula e se preparar para enfrentar os desafios de sua carreira. É nesse momento que os futuros docentes entrarão em contato pela primeira vez com a realidade educacional com um olhar para a formação dos alunos, além de poderem reconhecer as realidades histórica, social e cultural de seus futuros alunos (Scalabrin \& Molinari, 2013; Sousa \& Oliveira, 2021).

Para Salvador \& Souza (2021, p.4), existem situações que só podem ser vivenciadas no âmbito do Estágio Supervisionado:

A prática do estágio é muito enriquecedora, devendo ser realizada a partir de um planejamento adequado, que leve em consideração a realidade dos ambientes e sujeitos envolvidos, para que se constitua como espaço acolhedor entre as escolas e a universidade, contribuindo para o que o trabalho aconteça da melhor maneira. É sempre oportuno lembrar que as teorias frequentemente dão significado às práticas e estas, por sua vez, ressignificam as teorias a partir de situações singulares que só podem ser vivenciadas no espaço escolar. (Salvador \& Souza, 2021, p.4),

É no Estágio que a práxis se faz, e por meio dela, o futuro docente tem a oportunidade de ampliar sua visão relativa aos alunos e ao fazer pedagógico, uma vez que ao adentrar a sala de aula poderá identificar seus desafios, interesses e possibilidades. Contudo, para que esta ocasião seja de construção da identidade docente, a observação e regência durante o Estágio deve vir acompanhada da reflexão crítica do que está sendo observado (Scalabrin \& Molinari, 2013; Costa, 2021).

Deste modo, destaca-se a importância da relação entre as Universidades e as escolas, que precisa ser pautada pelo respeito e ganhos mútuos (Almeida, 2007). A escola como um local de portas abertas ao Estágio e à inovação, e a Universidade como contribuinte para a formação de professores cientes das necessidades educacionais. Segundo Sousa \& Martins (2020) essa relação, quando harmônica, é força motriz ao desenvolvimento de possibilidades diversificadas de atuação 
na realidade das escolas públicas. Milanesi (2012, p. 220) reforça que:

D’Ambrosio e Lopes (2015) afirmam, bem como Rojas, Souza \& Cintra (2008), que a educação brasileira necessita de professores que sejam criativos, ousados e capazes de motivar seus alunos na construção do conhecimento. Esse perfil de professor é capaz de refletir e reinventar seus métodos, atraindo a atenção de seus alunos e aumentando o sucesso da prática educativa. As autoras ainda fazem um convite:

Convido todos a considerarem o conceito de insubordinação criativa! Os professores devem ter a coragem e confiança para assumir riscos que são inovadores, criativos e resultam em invenções de novas possibilidades. Para isso eles deverão se apoiar num grupo que lhes dará respaldo, apoiando sua coragem para embarcar em ideias criativas em face de grande oposição. Professores devem ser agentes de mudança e transformação, se pretendemos investir na formação de crianças que conseguem atingir seu potencial humano máximo. (D’Ambrosio \& Lopes, 2015, p. 3)

Diante do exposto, e das demandas aqui apresentadas, esse trabalho tem por objetivo descrever e analisar a aplicação de uma sequência didática desenvolvida durante o período de Estágio Supervisionado da Licenciatura em Ciências Biológicas.

\section{Metodologia}

A pesquisa aqui desenvolvida trata-se de uma pesquisa qualitativa que tem como intuito a compreensão de fenômenos científicos e sociais e não somente salientar conceitos específicos. Dentro dessa abordagem, a ênfase se baseia mais nas interpretações de acontecimentos, do que em dados sistematizados. Devido ao fato desta pesquisa constituir-se em um relato de experiências, esta não se restringe à apresentação de resultados metódicos e precisos, mas sim por um desenvolvimento de eventos sociais, durante a prática docente em meio ao Estágio Supervisionado. Essa pesquisa qualitativa, não tem objeto controlar os dados coletados, mas sim captar o contexto em toda a sua totalidade, mediante a uma análise das informações discursadas, onde usa-se mais a intuição, e ainda assim, não deixa de ser uma pesquisa organizada (Pitanga, 2020).

Nessa pesquisa utilizou-se ferramentas comuns ao desenvolvimento de um Estágio Supervisionado em licenciatura, como o caderno de campo, onde o docente/estagiário faz anotações, tanto no período de observação quanto na regência, de seus relatos pessoais da experiência.

\subsection{A construção e aplicação da sequência didática durante o estágio supervisionado}

O trabalho aqui descrito teve como premissa o trabalho com os conteúdos conceituais relativos à anatomia, morfologia e importância ecológica do filo Arthropoda. Além disso, objetivou o desenvolvimento de conteúdos atitudinais e procedimentais inerentes à educação científica em uma turma de segunda série do Ensino Médio de uma Escola Estadual no município de Itajubá, MG. Concomitantemente foram realizadas aulas práticas e teóricas na Universidade Federal de Itajubá (UNIFEI) onde foram discutidas e construídas, de forma coletiva, as sequências didáticas a serem aplicadas durante o Estágio. Sob orientação da professora da disciplina de Estágio, as sequências didáticas construídas deveriam ser estruturadas em quatro fases, de acordo com as orientações de Aguiar Jr. (2017):

Fase 1: Problematização inicial: introduzindo o conteúdo

Fase 2: Desenvolvimento da narrativa do ensino

Fase 3: Aplicando os conhecimentos

Fase 4: Refletindo sobre o que foi aprendido 
A fase 1: "Problematização inicial: introduzindo o conteúdo" consistiu em um momento dialógico onde a estagiária, professora em formação, buscou levantar os conhecimentos prévios dos alunos sobre o filo Arthropoda. Para tal realizou um debate aberto com a proposição de questões como "Vocês já ouviram falar nos Artrópodes? O que eles são? Porque é importante estudá-los? Se eles fossem extintos, o que poderia acontecer nos ecossistemas?". As respostas dos alunos durante o debate promovido pelos questionamentos iniciais foram anotadas em caderno de campo e serviram como base para a construção das demais etapas da sequência didática.

Após esse questionamento inicial foi realizada a exibição do filme de animação "Bee Movie- A História de uma Abelha", lançado no ano de 2007, dirigido por Steve Hickner e Simon J. Scomum. A exibição do filme teve como objetivo contextualizar o estudo sobre Artrópodes e despertar o interesse dos alunos pela temática. Após sua exibição foram propostas questões sobre o filme a fim de que os alunos levantassem hipóteses e discutissem sobre a importância ecológica das abelhas.

Durante a fase 2: "Desenvolvimento da narrativa do ensino" foi utilizada uma apresentação multimídia em slides, contendo gifs e pequenos vídeos para ilustrar as características do filo Arthropoda. Nessa apresentação foram sistematizados conceitos sobre a fisiologia, anatomia, reprodução e importância ecológica dos representantes do filo, além das particularidades dos membros de suas classes: Arachnida, Chilopoda, Crustacea, Diplopoda e Insecta. Os conteúdos conceituais abordados nessa fase tiveram como base os conhecimentos prévios identificados na fase 1.

A fase 3: "Aplicando os conhecimentos" consistiu na construção, pelos alunos, de modelos didáticos da anatomia de exemplares das classes do filo Arthropoda. Essa etapa foi inspirada no trabalho de Beserra \& Brito (2012) que utilizou materiais de baixo custo, tais como materiais recicláveis (garrafas pet, restos de arame, entre outros), massa de modelar e biscuit, para a realização de modelagem. Os autores sugerem que as aulas práticas de modelagem sejam realizadas após as aulas teóricas, para que os alunos possam reconhecer as estruturas de alguns representantes do grupo para posteriormente realizarem a modelagem.

Nessa fase os alunos foram convidados a se reunir em grupos para construírem reproduções da anatomia de cada uma das classes do filo. Os alunos foram orientados a observarem detalhes dos animais, para uma melhor identificação e diferenciação das classes. Para a produção das peças, eles se apoiaram em imagens e desenhos de várias espécies como borboletas, besouros, gafanhotos, crustáceos, escorpiões, entre outras, contidas no livro didático.

Utilizou-se massa de biscuit de modelar para a realização da atividade proposta, e para a pintura dos materiais foi fornecido aos alunos tinta de tecido. Na Figura 1 observa-se o momento de pintura dos modelos produzidos pelos alunos. 
Research, Society and Development, v. 10, n. 13, e578101321179, 2021

(CC BY 4.0) | ISSN 2525-3409 | DOI: http://dx.doi.org/10.33448/rsd-v10i13.21179

Figura 1: Fotografia da modelagem e pintura realizada por um aluno de uma lagosta, crustáceo.

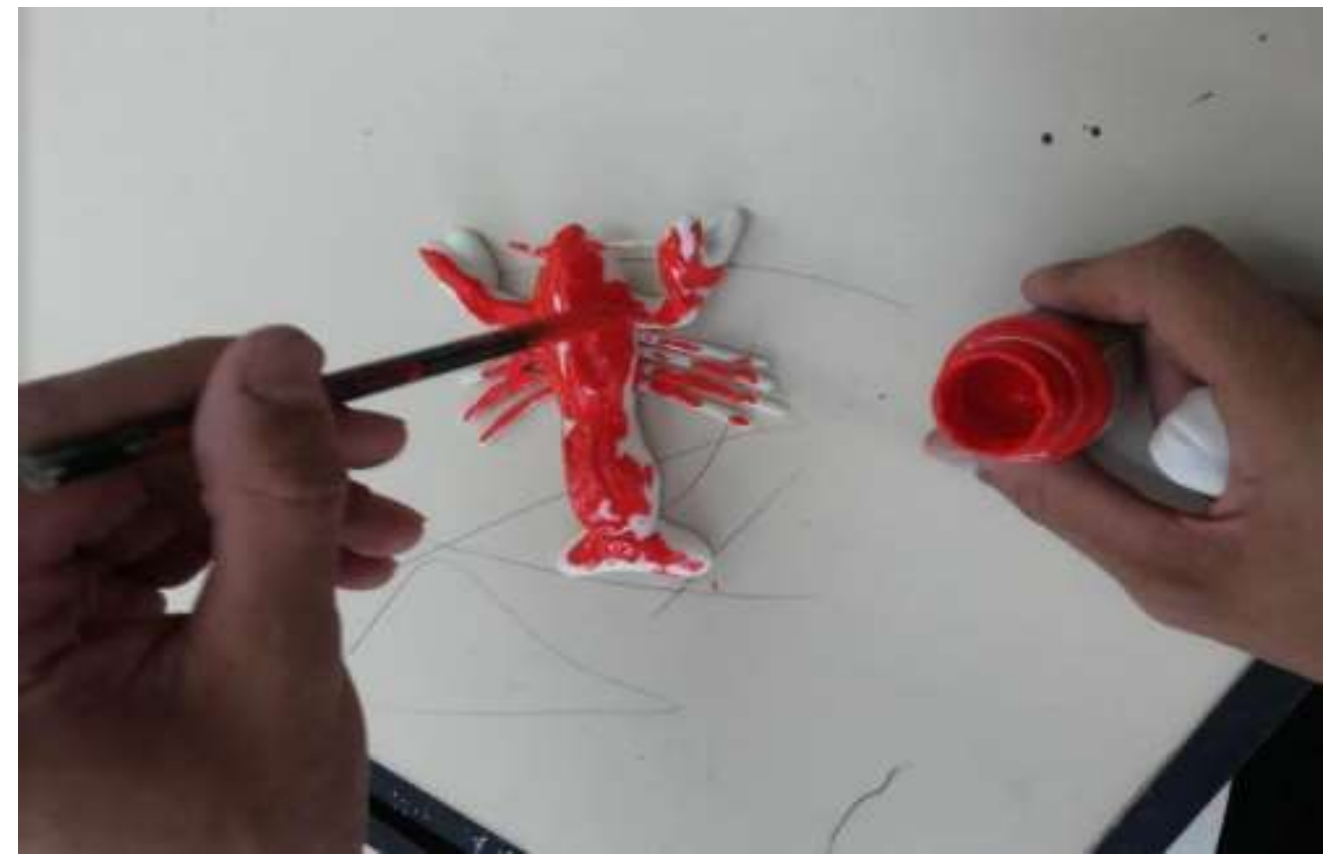

Fonte: Acervo da autora.

Para auxiliar na confecção dos modelos e melhor visualização das estruturas morfológicas dos animais, a estagiária levou para a sala de aula alguns exemplares de crustáceos e aracnídeos, conservados em álcool 70\%, da coleção zoológica da Universidade. Essa etapa foi de grande relevância uma vez que nenhum dos alunos havia visto um crustáceo. Na Figuras 2 são apresentados alguns dos modelos produzidos pelos alunos:

Figura 2: Fotografia de alguns dos exemplares produzidos e expostos pelos alunos.

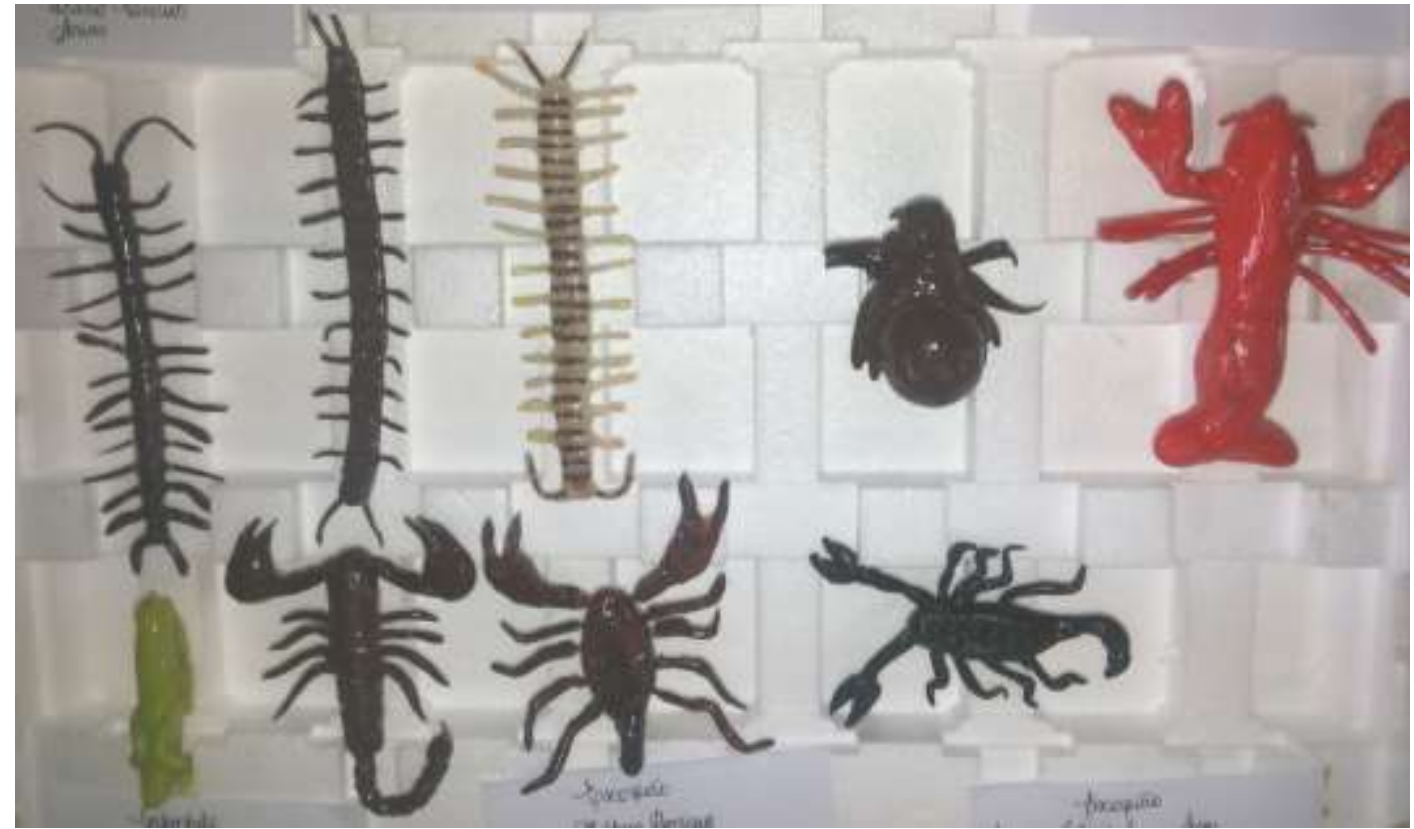

Fonte: Acervo da autora. 
Pode-se observar a criatividade na elaboração dos exemplares de biscuit e a diversidade de detalhes exibidos nas imagens. Alguns dos alunos se assentaram sozinhos, outros em duplas e até em trios para o desenvolvimento desta atividade. Um dos alunos, que fez o escorpião, comentou a possibilidade de trabalhar com atividades artesanais e que desconhecia esta sua habilidade de fazer arte. Outra aluna fez uma borboleta, com o corpo de biscuit e utilizou um de seus adesivos para fazer asas da mesma. Também, repara-se na Figura 3 os detalhes dos segmentos da estrutura de cada classe de Artrópodes apresentada nos modelos criados pelos alunos.

Figura 3: fotografia de alguns dos exemplares produzidos e expostos pelos alunos.

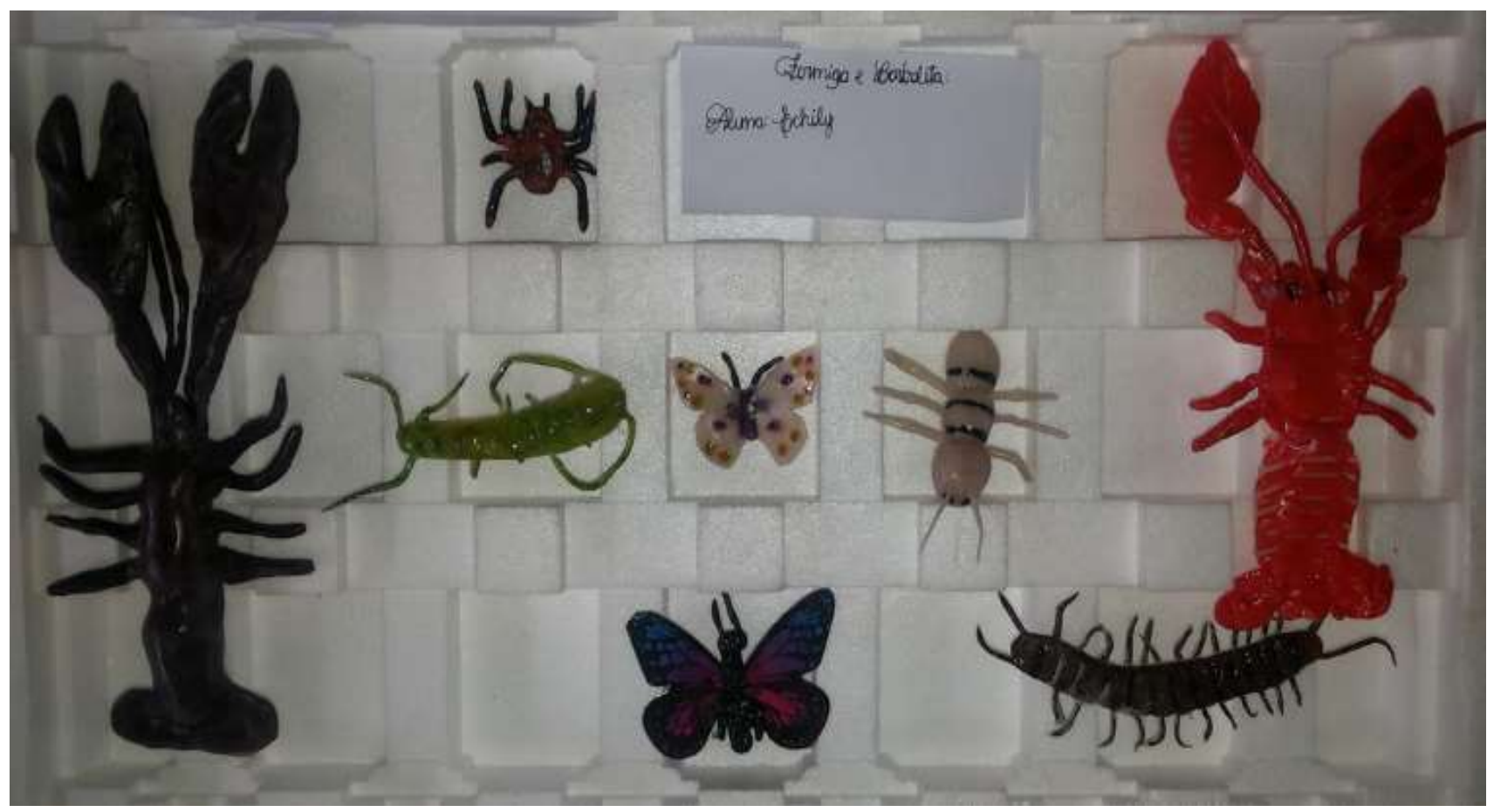

Fonte: Acervo da autora.

Após a construção dos modelos, os alunos realizaram uma exposição para os demais colegas da escola das peças produzidas (Figura 4). Durante a exposição os grupos apresentaram seus trabalhos e explicaram o porquê da escolha de tal animal, sua importância ecológica, forma de reprodução e detalhes de sua morfologia. Eles puderam consultar o livro didático para essa apresentação, caso tivessem alguma dúvida em suas explicações. 
Figura 4: Exposição das peças Fonte: Acervo da autora.

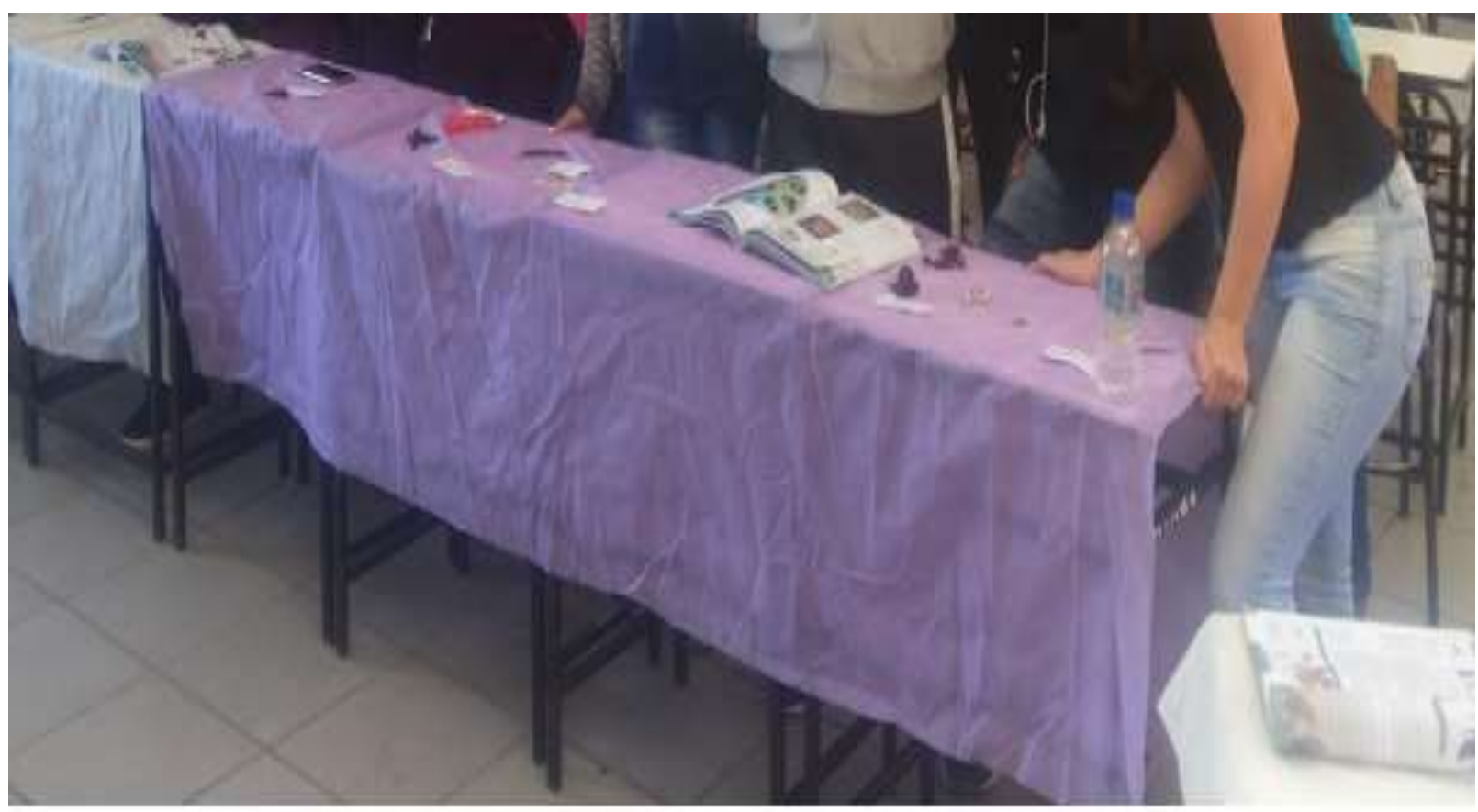

Fonte: Acervo da autora.

Na Fase 4: "Refletindo sobre o que foi aprendido" foram propostas aos alunos questões sobre o conteúdo para que eles pudessem sistematizar os conceitos trabalhados por meio da sequência didática. As questões buscavam mobilizar conceitos relativos à ecologia dos representantes do filo, suas classes, exemplos, morfologia e reprodução. A avaliação dos alunos se deu de modo formativo e processual durante as atividades práticas de modelagem, exposição dos materiais e realização do questionário final.

\section{Resultados e Discussão}

No período inicial, anterior à docência, do Estágio Supervisionado, foi possível observar e refletir sobre o perfil dos alunos da escola, além das estratégias e instrumentos utilizados pelos professores. Nesse ambiente, foi possível verificar o amplo acesso à tecnologia pelos alunos, e a distração deles durante a maioria das aulas. A escolha das estratégias e instrumentos utilizados na sequência didática, aqui descrita, levou em conta esse perfil dos alunos, com o objetivo de motivar a interação e interesse deles pelos conceitos em estudo.

Quando desenvolveu-se a Fase 1, os alunos ficaram amplamente motivados por poderem fazer algo novo, diferentemente da tradicional prática de copiar o conteúdo do livro didático, além do uso tradicional da lousa. Assistir ao filme para eles foi algo inovador uma vez que tais alunos não conheciam a animação e, mesmo o filme tendo sido lançado no ano de 2007, o mesmo possui artes gráficas e imagens 3D bem elaboradas e atraentes. Os conceitos de Preservação do Meio Ambiente atrelados ao filme, como a importância das abelhas para a polinização, despertou nos alunos um senso crítico sobre a ação da sociedade em questões como desmatamento e poluição. Percebeu-se ainda que durante a exibição do filme os alunos tiveram a oportunidade de relacionar o conteúdo em estudo com seu cotidiano, percebendo a aplicabilidade desses conceitos na compreensão da natureza.

Na Fase 2: "Desenvolvimento da narrativa do ensino", os alunos participaram ativamente realizando questionamentos, 
interagindo e relacionando o conteúdo por meio de exemplos. Foi possível perceber que o uso da tecnologia na sala de aula, por meio do conteúdo dos slides atraiu a atenção dos alunos, tornando as aulas mais dinâmicas, dialógicas e interativas. Na fase 3 "Aplicando os conhecimentos", quando se deu a prática de modelagem, foi fundamental para a aproximação dos alunos com o conteúdo conceitual como orientado por Marques- Filho et al. (2021).

Os alunos são residentes do estado de Minas Gerais, muitos nunca tiveram a oportunidade de ir ao litoral e até mesmo ver pessoalmente um crustáceo. Desse modo, a apresentação aos alunos de exemplares reais de crustáceos e aracnídeos, os ofereceu a oportunidade de conhecerem esses animais, auxiliando em sua compreensão sobre os aspectos morfológicos destes, além de auxiliar no processo de modelagem em biscuit. A utilização da modelagem como estratégia de ensino levou, como observado, os alunos a romperem com as dificuldades inerentes ao conteúdo e os levou a uma prazerosa e gratificante forma de se relacionar com o conhecimento, como propôs Camargo e Justus (2014, p. 5): "Então, o uso da modelagem nestas aulas poderá facilitar a aprendizagem dos conteúdos, possibilitando a incorporação dos conceitos, solucionando as dificuldades dos alunos e tornando as aulas mais interessantes e prazerosas, pois o conhecimento passa a ter novos significados."

Durante a correção do questionário e da exposição dos modelos produzidos pelos grupos de alunos foi possível observar que os mesmos compreenderam conceitos importantes para o estudo sobre Artrópodes. Podemos observar isso frente ao uso de conceitos como: polinização, muda, ecdise, metamorfose, entre outros. A estratégia de trabalhar em grupos aumentou a interação entre os alunos e os incentivou na realização da tarefa, contribuindo para o desenvolvimento de conteúdos para além dos conceituais, como também dos atitudinais e procedimentais inerentes ao processo de construção do conhecimento científico. Alguns dos alunos inicialmente se recusaram a realizá-la, mas ao verem os demais colegas produzindo os modelos foram incentivados e participaram ativamente da tarefa. A observação dos espécimes levados, despertou também o interesse e a curiosidade desses alunos. Nesse momento a passividade de muitos foi rompida.

Como aponta Freire (2005), no processo educativo todos acabam sendo educados, tanto alunos quanto professores, ao compartilhar o conhecimento, em uma troca constante; o docente aprende o que é ser docente, quando ele se dispõe a aprender com seus alunos. Sendo as vivências do Estágio essenciais para se conhecer o perfil dos alunos, a didática real dentro da sala de aula, a realidade sociocultural dos alunos, além da possibilidade de se compartilhar experiências com professores experientes, as satisfações e dificuldades da carreira.

No estágio, também foi possível, colocar em prática os conhecimentos construídos durante as aulas teóricas e práticas na Universidade. Com destaque para a importância do professor como mediador, conforme discute Santos (2021):

Dentro das competências: científica, técnica, humana e política desenvolvidas pelo professor, é essencial propiciar aos alunos condições para o desenvolvimento da capacidade de pensar crítica e logicamente, fornecendo-lhes meios para a resolução dos problemas inerentes aos conteúdos trabalhados interligados ao seu cotidiano, fazendo com que ele compreenda que o estudo é mais do que mera memorização de conceitos e termos científicos transmitidos pelo professor ou encontrados em livros. (Santos, "Trabalhando Com Alunos: Subsídios E Sugestões”, 2021)

A partir de quando compreende-se que o aluno não é simplesmente um ser inativo, que está naquele local somente para absorver informações, mas sim como um indivíduo que tem suas opiniões, saberes intrínsecos, uma história de vida, com questões socioeconômicas e culturais, e pode ser ativo, a formação docente conquista êxito. Pois, somente quando tem-se a compreensão de que outro é diferente e há o respeito, compreende-se melhor que ações diversas precisam ser trabalhadas para que o aprendizado seja facilitado ao aluno. 


\section{Conclusão}

Conclui-se o trabalho desenvolvido no decurso do Estágio, por meio da sequência didática aqui descrita, foi possível atingir os objetivos pedagógicos de construção coletiva, ativa e participativa do conhecimento científico, por meio de estratégias e instrumentos didáticos diversos. Mesmo diante dos recursos físicos escassos na rede pública de ensino foi possível, a partir da observação sobre nossos alunos, produzir e utilizar meios simples e econômicos para auxiliar na sua aprendizagem. Ao analisar o âmbito escolar, o docente pode inovar, na produção e promoção de aulas dinâmicas e não mais positivistas. Deste modo, o estágio se torna um passo decisivo para o futuro formando, é nesse momento que o profissional da educação aprende, ensina, compartilha e decide seguir a sua carreira. Esta pesquisa demonstra que a utilização de metodologias e instrumentos diversificados e dialógicos tende a atrair os alunos, e promover a formação de cidadãos críticos, ativos e propensos a mudanças. A metodologia didática descrita possui baixo custo e grande potencialidade, podendo ser replicado no estudo de outros filos.

\section{Referências}

Aguiar Jr, O. G. (2005). Módulo II: O Planejamento De Ensino. Projeto Escolas-Referência - Desenvolvimento Profissional De Educadores. Governo Do Estado De Minas Gerais. Secretaria De Estado De Educação, Belo Horizonte.

Alarcão, I. (2007). Professores Reflexivos Em Uma Escola Reflexiva. 5 Ed. São Paulo: Cortez.

Almeida, P. C. A. (2007) Saberes docentes e formação inicial de professores: implicações e desafios para as propostas de formação. Educação E Pesquisa, São Paulo, 33(2), 281-295

Araújo, C. R., \& Lopes Neta, N. A. (2017) O ensino tradicional e inovador para a aprendizagem de matemática na modalidade EJA. Saberes Docentes Em Ação. 3(1). http://Www.Maceio.Al.Gov.Br/Wp-Content/Uploads/2017/09/Pdf/2017/09/4-As-Implica\%C3\%87\%C3\%95es-Do-Ensino-Tradicional-EInovador-Para-A-Aprendizagem-De-Matem\%C3\%81tica-Na-Modalidade-Eja-Ni-1.Pdf

Achterberg, G., Centa, F., \& Terrazzan, E. (2021). Entre a memorização e a interação: a construção do perfil dos estudantes de ensino médio. E-Mosaicos, $10(23), 85-106$

Bastos, M. H. C. (2008). Do quadro-negro à lousa digital: a história de um dispositivo escolar. Cadernos De História Da Educação, 4. http://www.seer.ufu.br/index.php/che/article/view/391

Barbosa, F. D. D., Mariano, E. de F., \& Sousa, J. M. de. (2021). Tecnologia e Educação: perspectivas e desafios para a ação docente. Conjecturas, 21(2), 3860 .

Freire, P. (2005). Pedagogia Do Oprimido. 43 Ed. Rio De Janeiro, Paz E Terra.

Beserra, J. G.; Brito, C. H. (2012). Modelagem didática tridimensional de artrópodes, como método para ensino de ciências e biologia. R. Bras. De ensino de C\&T. 5(3), 70-88.

Lei 11.788 de 25 de Setembro de 2008. (2008). Dispõe sobre o estágio de Estudantes. http://Www.Planalto.Gov.Br/Ccivil_03/_Ato20072010/2008/Lei/L11788.Htm

Cabral, E. A. \& Stahl, J. C. R. (2021). A interação do conhecimento com os ambientes tecnológicos. Revista Brasileira de Desenvolvimento. Curitiba, 7(5), 52790 .

Camargo, F.; Daros, T.(2018). A sala de aula inovadora - estratégias pedagógicas para fomentar o aprendizado ativo. Penso Editora. https://curitiba.ifpr.edu.br/wp-content/uploads/2020/08/A-Sala-de-Aula-Inovadora.pdf

Camargo, E. A. B.; \& Justus, J. F. C. (2014). Os desafios da escola pública paranaense na perspectiva do professor PDE - artigos - modelagem didática de artrópodes. Cadernos PDE, Persão
http://www.diaadiaeducacao.pr.gov.br/portals/cadernospde/pdebusca/producoes_pde/2014/2014_uepg_cien_pdp_eloa_aparecida_boguchesky.pdf

Castilho, a., Araújo, J., \& Júnior, W. (2020). Relato de experiência do uso de websites na prática docente e seus desafios na formação da aprendizagem autônoma. Anais Do CIET:EnPED:2020 - (Congresso Internacional De Educação E Tecnologias | Encontro De Pesquisadores Em EducaçãO A DistâNcia). https://cietenped.ufscar.br/submissao/index.php/2020/article/view/1742

Correia, D. B., Gurgel, C. L., Alves , R. S., Bessa, F. G. C. de L. ., Torres , C. M. G. ., Macedo , G. F. ., Fidelis , K. R. ., Figueirêdo , F. V. ., Silveira , S. W. T. ., Araújo, E. F. de ., Barros , C. V. M. ., Oliveira, M. G. de ., Santos , L. T. dos ., Sampaio , R. S. L. ., Silva , V. B. da ., \& Almeida-Bezerra, J. W. (2021). As manifestações da Corrente Positivista na Educação Científica. Research, Society and Development, 10(2), e42610212708. https://doi.org/10.33448/rsdv10i2.12708

Costa, J. S. (2021) Relato de experiência do estágio supervisionado no curso de Pedagogia: o trabalho pedagógico no ensino remoto no contexto de pandemia no Bloco Inicial de Alfabetização. Cadernos de Estágio, 3 (1) 1-8. 
D’Ambrosio, B. S.; Lopes, C. E. (2015) Insubordinação criativa: um convite à reinvenção do educador matemático. Bolema, Rio Claro, $29(51)$, 1-17.

Faria, R. W. S. De C. (2019). Os conteúdos da aprendizagem e o raciocínio proporcional. RELVA, Juara/MT/Brasil, 6(1), $251-272$.

Gadotti, M. (2003). Saber Aprender: Um Olhar Sobre Paulo Freire E As Perspectivas Atuais Da Educação. In: Linhares, Célia; Trindade, Maria. Compartilhando O Mundo Com Paulo Freire. São Paulo; Cortez: Instituto Paulo Freire.

Lima, M. E. C. C.; Aguiar, O. G. J.; Braga, S. A. M. (2000). Ensinar Ciências. Revista Presença Pedagógica: Dicionário Crítico Da Educação. 6(33), 90-92.

Lozada, C. de O., Viana, S. L. da S., Oliveira, M. L. da S., Santos, B. G. dos, Lima, C. de A., \& Aviz, W. M. de A. (2021). Recursos didáticos para a formação de conceitos de probabilidade nos anos iniciais do ensino fundamental. Diversitas Journal, 6(1), 1638-1647.

Marques Filho, E. G., Moraes, L. G. da R., Macêdo, I. D. C., \& Melo, F. M. S. (2021). Educação freireana em comunidades quilombolas e implementação do ensino de História na comunidade Manga/Iús no município de Batalha, Piauí. Revista De Educação Popular, 471-490.

Milanesi, I. (2012) Estágio Supervisionado: Concepções e Práticas em Ambientes Escolares. Educar em Revista, Curitiba, (46) $209-227$.

Ministério Da Educação. (2007). Formação Continuada A Distância De Professores Para O Atendimento Educacional Especializado - Deficiência Visual. http://portal.mec.gov.br/seesp/arquivos/pdf/aee_dv.pdf

Oliveira, L. G. (2015). Super Almanaque de ciências da professora Genna: Uso didático de histórias em quadrinhos para o ensino de genética no Ensino Fundamental. 208f. Dissertação (Mestrado Em Educação) - Instituto De Ciências Humanas E Sociais, Universidade Federal De Ouro Preto, Mariana.

Pitanga, A. F. (2020). Pesquisa qualitativa ou pesquisa quantitativa: refletindo sobre as decisões na seleção de determinada abordagem. Revista Pesquisa Qualitativa. São Paulo (SP), 8(17), 184-201.

Pereira, B. T.; Freitas, M. C. D. (2021). O Uso Das Tecnologias Da Informação E Comunicação Na Prática Pedagógica Da Escola. http://www.diaadiaeducacao.pr.gov.br/portals/pde/arquivos/1381-8.pdf

Rojas, J.; Souza, R. A. M.; Cintra, R. C. G. G. (2008). Dinâmica Do Trabalho E A Organização Do Espaço Na Educação Infantil. Cuiabá: Edufemat.

Rossasi, L. B.; Polinarski, C. A. (2007). Reflexões sobre metodologias para o ensino de biologia: uma perspectiva a partir da prática docente. http://www.diaadiaeducacao.pr.gov.br/portals/pde/arquivos/491-4.pdf.

Salvador, M., Morais, N., \& Souza, N. (2021). Entre Contextos e Práticas: a importância do Estágio Supervisionado para a formação docente e para as relações entre Universidade e Escola. Revista EducaçãO GeográFica Em Foco, 5(9), 15-19.

Santos, E. S. (2021). Trabalhando Com Alunos: Subsídios E Sugestões, O Professor Como Mediador No Processo Ensino Aprendizagem. Revista Do Projeto Pedagógico. Gestão Universitária, Edição 40. http://www.udemo.org.br/revistapp_02_05professor.htm

Sousa, A. O. \& Oliveira, M. A. (2021). Estágio Supervisionado. Brazilian Journal of Development, Curitiba,7(1), p.7692-7703

Sousa, L. M. de, Indjai, S., \& Martins, E. S. (2020). Formação inicial de docentes de biologia: limites e possibilidades do Estágio Supervisionado no ensino médio. Práticas Educativas, Memórias E Oralidades - Rev. Pemo, 2 (2), 1-12.

Scalabrin, I. C., \& Molinari, A. M. C. (2013). A Importância da Prática do Estágio Supervisionado nas Licenciaturas. Unar-Revista Científica. 7(1) http://revistaunar.com.br/cientifica/documentos/vol7_n1_2013/3_a_importancia_da_pratica_estagio.pdf

Terçariol, A. A. L.; Barros, d. M. V.; \& Gitahy, R. R. C. (2021). Os estilos de uso dos espaços virtuais na construção de estratégias didáticas na licenciatura e na formação para a docência na educação básica. Interfaces da Educ., Paranaíba, 12(34), 1012-1040.

Vieira Júnior, I. L. \& Melo, J. C. (2021). Utilizando as tecnologias na educação: possibilidades e necessidades nos dias atuais. Brazilian Journal of Development, Curitiba, 7(4), 34301-34313. 